\title{
Effects of dietary fibre on faecal steroid measurements in baboons (Papio cynocephalus cynocephalus)
}

\author{
S. K. Wasser ${ }^{1}$, R. Thomas ${ }^{1,2}$, P. P. Nair ${ }^{2}$, C. Guidry ${ }^{2}$, J. Southers ${ }^{3}$, \\ J. Lucas ${ }^{3}$, D. E. Wildt ${ }^{1}$ and S. L. Monfort ${ }^{1}$ \\ ${ }^{1}$ National Zoological Park, Conservation and Research Center, Smithsonian Institution, Front Royal, \\ VA 22630, USA; ${ }^{2}$ Lipid Nutrition Laboratory, US Department of Agriculture, Beltsville, MD 20705, \\ USA; and ${ }^{3}$ Primate Research Unit, National Institutes of Health, Bethesda, MD 20892, USA
}

\begin{abstract}
A study was conducted in captive baboons to determine (i) the impact of cereal dietary fibre on faecal progestogen excretion, and (ii) whether means of controlling dietary effects could be identified. Blood was collected on 3 days per week and faeces on 5 days per week from four unanaesthetized cyclic female baboons, consecutively fed three diets of 5,10 and $20 \%$ fibre for 90 days per diet. A 2 day lag time was detected before progesterone in the blood appeared in the faeces, regardless of diet (mean correlation was $0.62, P=0.002$ ). Increased dietary fibre had a negative effect on progestogen excretion $(P<0.004)$. Correspondence between blood and faecal progestogens was consistently greatest and the effect of dietary fibre least when faecal progestogens were expressed $\mathrm{g}^{-1}$ dry faeces. Several means of indexing faecal steroid excretion rates were examined including dehydroepiandrosterone (DHEA) and a number of byproducts of cholesterol metabolism. The cholesterol metabolite, cholestanone, was positively correlated with dietary fibre $(r=0.27 ; P<0.04)$. Multiplying faecal progestogen concentration by the cholestanone $g^{-1}$ dry faeces concentration increased the correlation between serum and cholestanone-indexed faecal progestogens $(r=0.78, P=$ $0.0001)$ compared with nonindexed progestogens $(r=0.71, P=0.0001)$. We conclude that expressing faecal progestogens $\mathrm{g}^{-1}$ dry faeces may be sufficient and the most cost-effective method for controlling for most dietary effects when the objective is monitoring longitudinal endocrine status in baboons. However, it may be appropriate to express faecal progestogens by cholestanone concentrations when increased precision is needed to overcome the effects of profound variations in dietary fibre.
\end{abstract}

\section{Introduction}

Interest in techniques for monitoring faecal steroids has increased considerably (Shackleton, 1974; Adlercreutz and Jarvenpaa 1982; Shille et al., 1984; Möstl et al., 1984; Risler et al., 1987; SafarHermann et al., 1987; Perez et al., 1988; Wasser et al., 1988, 1991; Ziegler et al., 1988; Shideler et al., 1989; Kirkpatrick et al., 1990; Lasley and Kirkpatrick 1991). These noninvasive techniques have broad applications, permitting both longitudinal and experimental studies of reproductive and adrenal physiology in captive or free-ranging animals. Two factors influencing the accuracy of such techniques are (i) the degree to which diet affects steroid excretion and (ii) our ability to control for such effects. Dietary fibre has been reported to decrease gastrointestinal (GI) transit time, while increasing faecal bulk and total faecal oestrogen excretion in women (Goldin et al., 1981, 1982). This paper examines the degree to which cereal dietary fibre affects progestogen excretion in captive, yellow baboons (Papio cynocephalus cynocephalus) housed at the National Institutes of Health Primate Research Unit. Several hypothetical indices of steroid excretion rate, including dehydroepiandrosterone (DHEA) and several byproducts of cholesterol metabolism, were tested as possible methods for minimizing dietary effects.

Shideler et al. (1989) proposed that relatively high circulating basal concentrations of DHEA (or DHEA-S) result in a persistently high baseline excretion rate, regardless of dynamic changes in serum. If correct, DHEA metabolites would vary proportionally with GI transit time, thereby serving as an accurate excretion index for other faecal steroids. In theory, the DHEA hypothesis predicts that separate infusions of high and low doses of DHEA will result in peak faecal excretion of DHEA at approximately the same absolute concentrations, regardless of dose. However, the high dose will continue to be excreted at peak concentration for longer than the low dose. By contrast, peak excretion of other, similarly infused steroids (e.g. progestogens) in faeces will vary in proportion to the amount infused, and the excretion time course will be equivalent for both doses. We tested this hypothesis by simultaneously administering $\left[{ }^{3} \mathrm{H}\right] \mathrm{DHEA}$ and $\left[{ }^{14} \mathrm{C}\right]$ progesterone to female baboons.

Dietary fibre also appears to influence excretion and microfloral degradation of bile acids and neutral sterols, which, like 
steroid hormones, are products of cholesterol metabolism (Nair 1984; Nair et al., 1984; Turjman and Jacob 1984). Increased cereal dietary fibre decreases GI transit time and bacterial conversion of primary (cholic and chenodeoxycholic) to secondary (deoxycholic and lithocholic) bile acids, thereby increasing the proportion of primary to secondary bile acids excreted in faeces (Kurup et al., 1984). Cereal dietary fibre also increases faecal bulk, as well as excretion of the major cholesterol metabolites (coprostanol, coprostanone, cholestanol and cholestanone) in faeces (Nair et al., 1984). Analyses were conducted to determine whether the ratio of primary to secondary bile acids or the concentration of neutral sterols in faeces varied as a function of dietary fibre. The objective was to determine whether one or more of these metabolites might serve as an index of steroid excretion rate in faeces.

\section{Materials and Methods}

\section{Sample collection}

Four adult (7-10 year old) female baboons were each implanted with a catheter inserted into the femoral vein leading to a subcutaneous rubber bleeding port on the flank. Females were trained to present their flank for grooming, allowing blood samples to be withdrawn from the port by a syringe, without anaesthesia. Fresh faecal samples were collected (before 11:00 h) off a $0.6 \mathrm{~cm}$ mesh screen placed under each animal's cage, allowing urine to flow through freely into a stainless steel pan below. Blood and faecal samples were collected in the above manner 3 and 5 days per week, respectively, for 9 months, while females were fed on a diet containing 5, 10 and $20 \%$ cereal type fibre (3 months of each). All samples were frozen $\left(-20^{\circ} \mathrm{C}\right)$ until analysed. Diets were of a classical type consisting of a combination of soy, corn and alfalfa, prepared in pellet form by Marion Zoological, Inc. (Marion, Oklahoma). Crude protein was $25 \pm 1 \%$, fat was $5.5 \pm 0.5 \%$, and carbohydrates were about $17 \%$. The diets differed only in percentage of dietary fibre (source: soy bean husks). The fibre consisted of $60 \%$ neutral detergent fibre, $43 \%$ acid detergent fibre, 3.5\% acid lignon and $36 \%$ crude fibre. Animals were fed the same amount twice a day and generally consumed all pellets provided. The typical dietary fibre concentration of these captive baboons is about $6 \%$, compared with a variable average of about $20 \%$ in the wild.

\section{Sample extraction and faecal steroid analyses}

Faecal steroids were extracted using the technique developed by Wasser et al. (1991) with the following modification. The entire faecal sample was taken to dryness in a rotary evaporator (Savant, Farmingdale, NY), mixed thoroughly and $0.2 \mathrm{~g}$ boiled for $20 \mathrm{~min}$ in $10 \mathrm{ml}$ ethanol. The boiling method improved overall recovery of labelled progestogen-metabolites from 71 to $84 \%$. These recovery estimates were conservative, based upon extraction of naturally metabolized, radiolabelled steroids infused into the animals (in contrast to $>90 \%$ recovery of $\left[{ }^{3} \mathrm{H}\right]$ progesterone added to each sample before processing). Progestogen concentrations were measured in extracted faecal samples using radioimmunoassay procedures described by
Wasser et al. (1991). The assay used a monoclonal progesterone antibody made against the hemisuccinate of $11 \alpha$-hydroxyprogesterone coupled to BSA (Greiger et al., 1990). Coefficients of variation for extraction and assay of two separate internal controls (pooled faecal samples containing high concentrations of oestradiol and progesterone and low concentrations of oestradiol and progesterone, respectively) were both $12.0 \%$ for oestradiol and $9.5 \%$ for progesterone (8 extractions and assays each). Intra-assay coefficients of variation were $2.1 \%$ and $2.2 \%$ for the oestradiol and progesterone assays, respectively.

Faecal steroid concentrations were expressed per gram dry weight and per gram equivalent wet weight (determined by measuring the amount of water in the fresh sample and adjusting the dry material analysed to include the water contribution). These two values were compared to determine which one (i) provided the best correspondence with serum hormone concentrations, and (ii) was least affected by dietary fibre.

\section{Infusion of $\left[{ }^{3} \mathrm{H}\right] \mathrm{DHEA}$ and $\left[{ }^{14} \mathrm{C}\right]$ progesterone}

Two animals maintained on a constant $5 \%$ fibre diet were both administered (i.v.; about 09:00 h) a low and then a high dose (I month apart) of $\left[{ }^{3} \mathrm{H}\right] \mathrm{DHEA}(100 \mu \mathrm{Ci}$ low; $200 \mu \mathrm{Ci}$ high) and $\left[{ }^{14} \mathrm{C}\right]$ progesterone $(10 \mu \mathrm{Ci}$ low; $20 \mu \mathrm{Ci}$ high; NEN, Wilmington, DE). Females were checked hourly and all urine and faeces were collected within $1 \mathrm{~h}$ of voiding for $96 \mathrm{~h}$ after infusion.

\section{Bile acids and neutral sterol analyses}

Samples were analysed for neutral sterols (coprostanol, coprostanone, cholestanol and cholestanone) and primary (cholic and chenodeoxycholic) and secondary (deoxycholic and lithocholic) bile acids. Neutral sterols were analysed using a modification of techniques previously described by Turjman and Nair (1984) and Kurup et al. (1984), respectively. Lyophilized faeces $(100 \mathrm{mg}$ ) were extracted with ethanol/ammonia and saponified with sodium hydroxide in ethanol. Neutral sterols were extracted from this saponified mixture with hexane and measured by gas-liquid chromatography. The aqueous layer from the hexane extraction step was adjusted to $\mathrm{pH} 6.0$ and hydrolysed with cholyglycine hydrolase from Clostridium perfringens (ATCC 19574, USDA, Beltsville, MD; Nair et al., 1967). Unconjugated bile acids were isolated by reversed phase chromatography on C18 Spice cartridges (Rainin, Woburn, MA) and recovered by elution with $95 \%$ methanol. Bile acids were separated and measured by gas-liquid chromatography.

\section{Statistical analyses}

Simple and multiple linear regression analyses were used to determine the correspondence between serum progesterone and faecal progestogens as well as the effects of dietary fibre on faecal steroid excretion. Linear regression was also used to determine the effect of dietary fibre on excretion of neutral sterols. However, because the number of matched blood and faecal samples assayed for both neutral sterols and bile acids were small $(n=50)$, data from all four females were pooled, and animal identity was dummy-coded to control for individual 

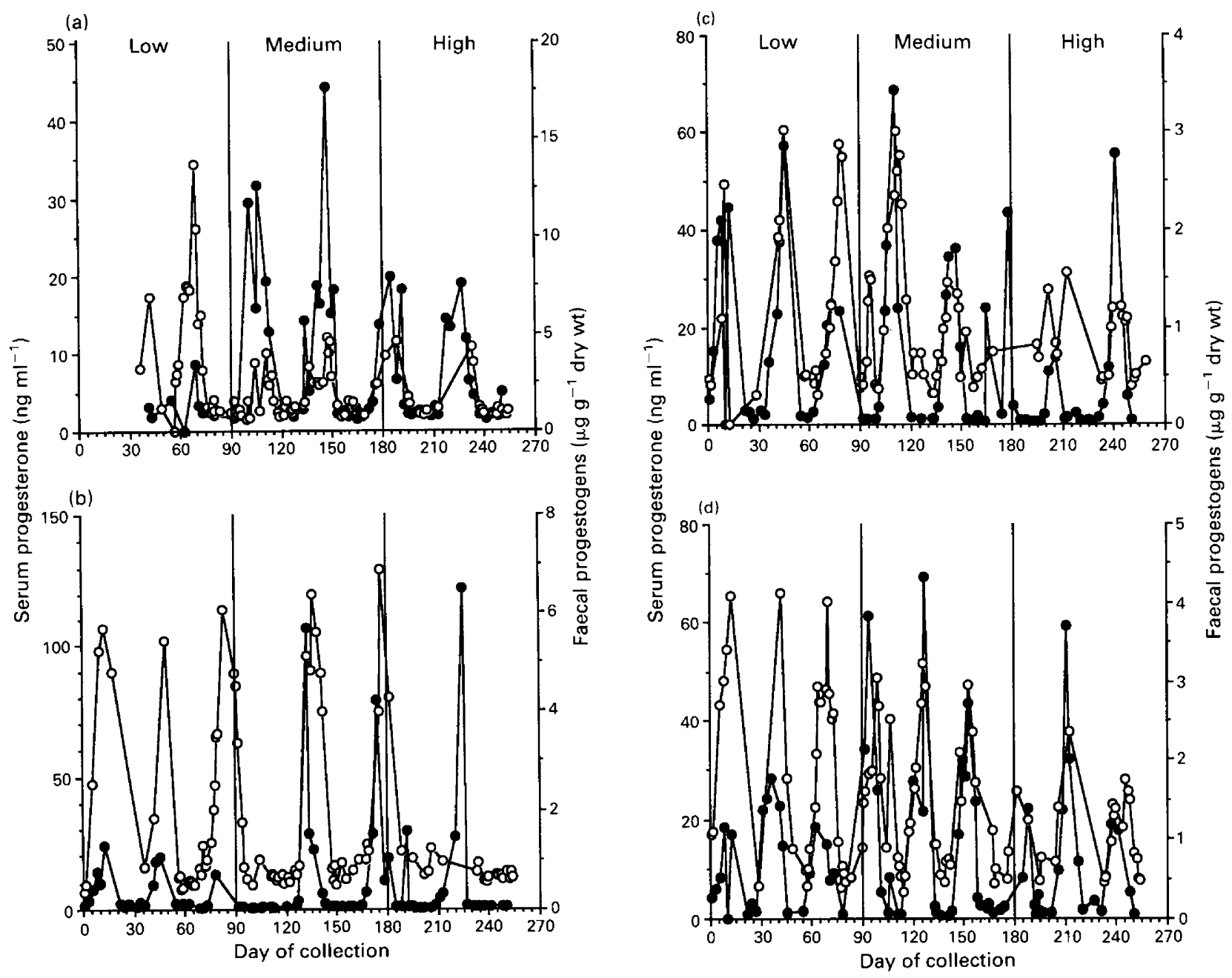

Fig. $1(\mathbf{a}-\mathbf{d})$. Correspondence between serum (ng ml-1; 0 ) and faecal $\left(\mu \mathrm{g} \mathrm{g}^{-1}\right.$ dry weight; $\left.\bigcirc\right)$ progestogens of four female baboons (animals $436,464,656$ and 848 , respectively), across a four-fold increase in dietary fibre for 9 months ( $5 \%$ fibre $=$ day 1 to $90 ; 10 \%$ fibre $=$ day 91 to $180 ; 20 \%$ fibre $=$ day 181 to 250 ).

differences. Potential indices demonstrating the predicted relationship between excretion and dietary fibre were used to index faecal progesterone concentrations. Indexed and nonindexed faecal progestogen concentrations were correlated separately with serum progesterone. Indices were considered effective if their use significantly improved $(P<0.05)$ the correlation between serum and faecal progestogens.

\section{Results}

\section{Serum and faecal progestogen profiles}

Serum progesterone concentrations were consistently the most predictive of progestogen concentrations in faeces collected 2 days later (Fig. 1). On this basis, there was excellent correspondence between blood and faecal progestogens in all animals, regardless of dietary fibre. As demonstrated below, these lag-time data were consistent with the approximate $40-50 \mathrm{~h}$ lag detected from the time of infusion of radiolabelled steroids in blood until their concentration peaked in faeces. It is noteworthy that the scales of both serum and faecal pro- gestogen concentrations vary markedly between females. Some of these differences can be explained by spikes in the steroid concentrations of one or two samples. For example, the faecal progestogen concentrations of animal 436 were comparable to those of the other three females, with the exception of two consecutively high faecal progestogen samples she voided at about day 75 (Fig. 1a). Among the four females, animal 464 (Fig. Ib) actually showed the most consistently high faecal progestogen concentrations; her serum progesterone concentrations were also the highest among the four females.

A significant effect of dietary fibre on variance of faecal progestogens was found $\left(t_{\text {fiber }}\right.$, Table 1$)$. The impact of dietary fibre on progestogen excretion $\mathrm{g}^{-1}$ dry faeces $(P<0.002)$ was significant when data from all animals were pooled and individual differences controlled by dummy-coding (Table I). However, when analysed by individual, dietary fibre improved $(P<0.05)$ prediction of faecal progestogen concentrations only for animal no. 848. (This animal also appeared to have the poorest serum-faecal progestogen correspondence of the group.) In all cases, increased dietary fibre decreased progestogen excretion $\mathrm{g}^{-1}$ dry faeces (Table $\mathrm{I}$, Fig. 1 ), but presumably 
Table 1. Contribution of serum progesterone $\left(t_{\text {serum }}\right)$ and dietary fibre $\left(t_{\text {fibre }}\right)$ to a multiple regression model predicting variance in faecal progestogen concentrations, expressed $\mathrm{g}^{-1}$ wet, versus dry, weight

\begin{tabular}{|c|c|c|c|c|}
\hline & $r^{a}$ & $t_{\text {serum }}{ }^{b}$ & $t_{\text {fibre }}{ }^{b}$ & $n$ \\
\hline \multicolumn{5}{|l|}{ Overall $^{c}$} \\
\hline Progesterone $\mathrm{g}^{-1}$ wet weight & $0.63^{* *}$ & $6.60^{* *}$ & $-3.35^{*}$ & 111 \\
\hline Progesterone $\mathrm{g}^{-1}$ dry weight & $0.63^{* *}$ & $7.02^{* *}$ & $-3.12^{*}$ & 111 \\
\hline \multicolumn{5}{|l|}{ Animal 436} \\
\hline Progesterone $\mathrm{g}^{-1}$ wet weight & $0.63^{*}$ & $3.55^{*}$ & -1.65 & 27 \\
\hline Progesterone $\mathrm{g}^{-1}$ dry weight & $0.62^{*}$ & $3.59^{*}$ & -1.34 & 27 \\
\hline \multicolumn{5}{|l|}{ Animal 464} \\
\hline Progesterone $\mathrm{g}^{-1}$ wet weight & $0.62^{*}$ & $3.42^{*}$ & -1.38 & 26 \\
\hline Progesterone $\mathrm{g}^{-1} \mathrm{dry}$ weight & $0.65^{*}$ & $3.93^{*}$ & -1.30 & 26 \\
\hline \multicolumn{5}{|l|}{ Animal 656} \\
\hline Progesterone $\mathrm{g}^{-1}$ wet weight & $0.74^{* *}$ & $5.61^{* *}$ & -0.38 & 28 \\
\hline Progesterone $\mathrm{g}^{-1}$ dry weight & $0.74^{* *}$ & $5.56^{* *}$ & -0.67 & 28 \\
\hline \multicolumn{5}{|l|}{ Animal 848} \\
\hline Progesterone $\mathrm{g}^{-1}$ wet weight & $0.67^{*}$ & $2.84^{*}$ & $-3.32^{*}$ & 30 \\
\hline Progesterone $\mathrm{g}^{-1} \mathrm{dry}$ weight & $0.67^{*}$ & $3.09^{*}$ & $-3.03^{*}$ & 30 \\
\hline
\end{tabular}

${ }^{a} r=$ correlation coefficient of the entire regression model;

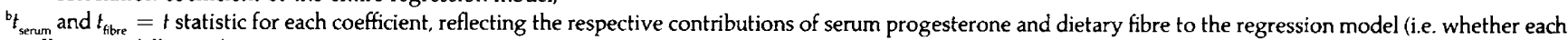
coefficient is different from 0 );

'Data pooled across individuals, controlling for individual differences by first entering individuals (dummy-coded) into the regression model;

${ }^{*} P<0.01 ;{ }^{* *} P<0.0001$ compared with the null model.

increased total faecal weight (Goldin et al., 1981, 1982). Overall, the serum-faecal correspondence in steroid concentrations $\left(t_{\text {serum }}\right)$ was best, and the effect of dietary fibre on faecal steroid excretion $\left(t_{\text {fiber }}\right)$ least, when faecal steroids were expressed $g^{-1}$ dry weight (versus $g^{-1}$ equivalent wet weight). This occurred if analyses were conducted upon individual females or with all females combined (Table 1).

The percentage of water in faeces increased with dietary fibre $(P<0.0001)$. However, the effect of percentage of water on faecal progestogen concentrations was significant only $(P<0.0001)$ for samples expressed $\mathrm{g}^{-1}$ wet (versus dry) weight. The effect of dietary fibre also remained significant in this model.

\section{$\left[{ }^{3} H\right] D H E A$ and $\left[{ }^{14} \mathrm{C}\right]$ progesterone excretion}

Forty per cent of infused progesterone was excreted into faeces after infusion of DHEA and progesterone compared with only $14 \%$ of DHEA (Fig. 2). The remainder of these two steroids was excreted in urine. Both $\left[{ }^{3} \mathrm{H}\right] \mathrm{DHEA}$ and $\left[{ }^{14} \mathrm{C}\right]$ progesterone followed the predicted progesterone pattern. Excretion of the high and low dose of both $\left.{ }^{3} \mathrm{H}\right] \mathrm{DHEA}$ and $\left[{ }^{14} \mathrm{C}\right]$ progesterone were directly proportional to the amounts infused, and excretion time was independent of dose. Peak excretion of both $\left[{ }^{3} \mathrm{H}\right] \mathrm{DHEA}$ and $\left[{ }^{14} \mathrm{C}\right]$ progesterone occurred approximately $45 \mathrm{~h}$ after infusion.

\section{Cholesterol metabolite and bile acid excretion}

On the basis of analyses of 60 faecal samples, virtually no primary bile acids (cholic and chenodeoxycholic) were found, eliminating use of the ratio of primary to secondary bile acids as a possible steroid excretion index. Of the four cholesterol metabolites examined, only cholestanone excretion corresponded to dietary fibre; cholestanone excretion increased proportionally $(P<0.04)$ with the amount of dietary fibre (Fig. 3). Cholestanone excretion was not affected $(P>0.05)$ by percentage of water in the sample (data not shown). When dietary fibre was used to predict faecal cholestanone and progestogen concentrations, the respective slopes of the two regression lines were of similar magnitude, but in opposing directions (Fig. 3). By contrast, the slope of the regression line using dietary fibre to predict cholestanone-indexed faecal progestogen concentrations (progestogen concentrations multiplied by the concentration of cholestanone found in the same sample) produced a slope not different $(P<0.05)$ from zero.

The utility of cholestanone $\left(\mathrm{g}^{-1}\right.$ dry faeces) as an index of faecal steroid excretion was tested by using serum progesterone concentrations to predict indexed versus nonindexed faecal progestogen content (lagged by 2 days). After controlling for individual differences (by dummy-coding), serum progesterone concentrations predicted more of the variance in cholestanoneindexed faecal progestogens than in nonindexed faecal progestogens (Table 2). Although the effect of fibre approached significance for the nonindexed samples, adding dietary fibre had no effect upon the regression models predicting cholestanoneindexed progestogens (Table 2).

\section{Discussion}

There was a close relationship between serum and faecal progestogen concentrations two days later, which confirmed our earlier observations (Wasser et al., 1988, 1991). New data also demonstrated that this correspondence was relatively independent of the amount of dietary fibre consumed and greatest when faecal progestogen concentrations were expressed $\mathrm{g}^{-1} \mathrm{dry}$ 


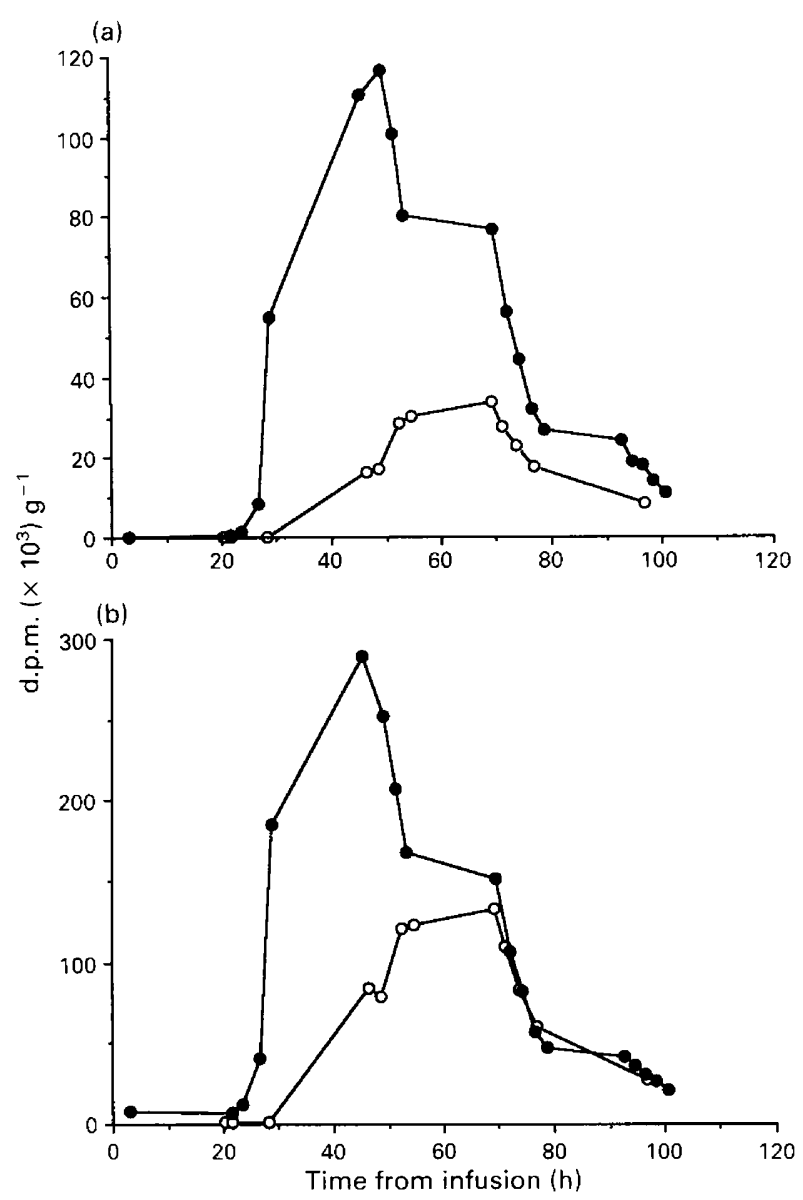

Fig. 2. Faecal excretion rate of infused (i.v.) radiolabelled (a) $\left[{ }^{14} \mathrm{C}\right]$ progesterone and $(b)\left[{ }^{3} \mathrm{H}\right] \mathrm{DHEA}$ at low $(\mathrm{O} ; 10 \mu \mathrm{Ci}$ for progesterone; $100 \mu \mathrm{Ci}$ for DHEA) and high doses $(0 ; 20 \mu \mathrm{Ci}$ for progesterone; $200 \mu \mathrm{Ci}$ for DHEA) in animal no. 848.

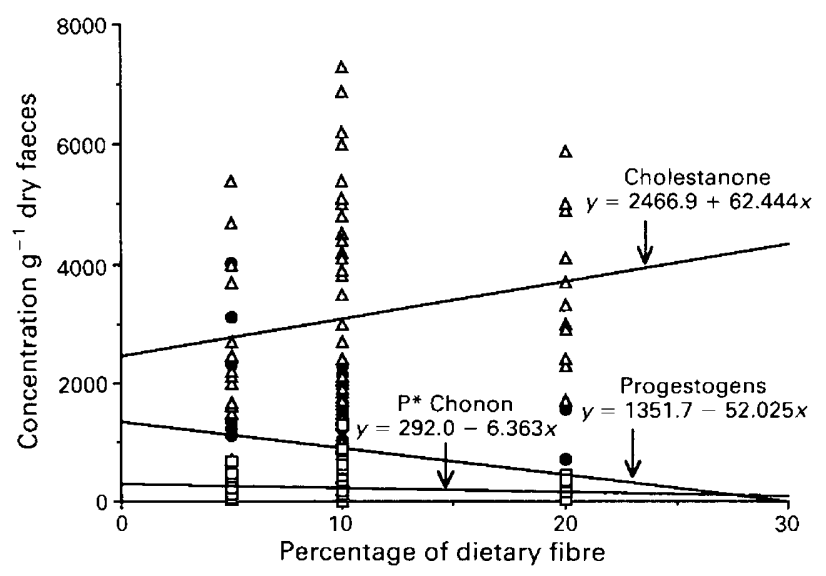

Fig. 3. Regression lines using dietary fibre to predict faecal progestogens $(\circlearrowleft)$, cholestanone $(\times 1000 ; \Delta)$ and cholestanone-indexed progestogens ( $\square$ ). P* Chonon: product of progesterone and cholestanone values from the same sample.
Table 2. Contribution of serum progesterone $\left(t_{\text {serum }}\right)$ and dietary fibre $\left(t_{\text {fibre }}\right)$ to multiple regression model predicting variance in cholestanone-indexed versus non-indexed faecal progestogen concentrations, expressed $\mathrm{g}^{-1} \mathrm{dry}$ weight

\begin{tabular}{|c|c|c|c|c|}
\hline & $r^{2}$ & $t_{\text {serum }}^{b}$ & $t_{\text {fibre }}{ }^{b}$ & $n$ \\
\hline \multicolumn{5}{|l|}{ Overall $^{c}$} \\
\hline \multicolumn{5}{|l|}{ Cholestanone $\times$ progesterone } \\
\hline $\mathrm{g}^{-1}$ dry weight & $0.78^{*}$ & $7.18^{*}$ & 0.71 & 49 \\
\hline Progesterone $\mathrm{g}^{-1}$ dry weight & $0.71^{*}$ & $4.85^{*}$ & -1.38 & 49 \\
\hline
\end{tabular}

${ }^{2} r=$ correlation coefficient of the entire regression model;

${ }^{b} t_{\text {serum }}$ and $t_{\text {fibre }}=t$ statistic for each coefficient, reflecting the respective contributions of serum progesterone and dietary fibre to the regression model;

'Data pooled across individuals, controlling for individual differences by first entering individuals (dummy-coded) into the regression model;

${ }^{*} P<0.0001$ compared with the null model.

(rather than $\mathrm{g}^{-1}$ equivalent wet) weight. It is well established that faecal bulk increases with dietary fibre, because of increases in both water and dry material (Goldin et al., 1982). Although overall changes in faecal bulk were not measured, the percentage of water was found to increase with dietary fibre. Fibre accounted for a significant additional portion of the variance in faecal progestogen concentrations expressed $g^{-1}$ wet or dry weight. However, percentage of water predicted a significant portion of the variance only for faecal progestogens $\mathrm{g}^{-1}$ wet weight. All of these observations supported the conclusion that faecal steroids were best expressed $\mathrm{g}^{-1}$ dry weight. Expressing faecal progestogens $\mathrm{g}^{-1}$ of dry, rather than wet, weight appeared to decrease the variance within individual progestogen profiles. This smoothing effect was most apparent by a reduction in high end outliers resulting from a low water percentage in some samples. However, Bamberg et al. (1991) reported an influence on low end outliers in severely diarrhetic samples; this effect should also be circumvented by expressing findings $\mathrm{g}^{-1}$ dry weight. Removing the influence of water (by expressing samples $\mathrm{g}^{-1}$ dry weight) apparently improves the serum to faecal progestogen correspondence because most faecal steroids are unconjugated and, therefore, relatively hydrophobic (Adlercreutz et al., 1979).

Absolute faecal progestogen concentrations $\mathrm{g}^{-1}$ dry (or wet) weight decreased as dietary fibre increased. This may have occurred because total $(24 \mathrm{~h})$ free steroid excretion: (i) was unaffected by dietary fibre, but faecal bulk increased; (ii) decreased because the increased dietary fibre reduced GI transit time and increased the proportion of conjugated steroid; or (iii) increased, but the increase was less than the increase in faecal bulk. Data from humans support the last explanation in that $24 \mathrm{~h}$ faecal oestrogen excretion increased with dietary fibre; however, the effect was eliminated in an analysis of covariance after adjusting for the simultaneous increase that occurred in faecal bulk (Goldin et al., 1981, 1982).

Of the potential indices of faecal steroid excretion examined, only cholestanone concentrations appeared useful in baboons. Indexing faecal progestogens by cholestanone (which was positively correlated with dietary fibre) eliminated the impact of diet on the concentration of progestogen excreted, while 
simultaneously improving correspondence with serum. However, based upon the close correspondence between serum and nonindexed faecal progestogens, regardless of dietary fibre, it may be impractical and unnecessary to rely on such an index, at least in this species. Simply expressing faecal progestogens $\mathrm{g}^{-1}$ dry weight may be sufficient and the most cost-effective approach for controlling dietary effects on steroid excretion to confirm the occurrence of ovulation and diagnose pregnancy or abortion. On the other hand, when increased precision is required for estimating absolute steroid concentrations (for example determining the magnitude of luteal phase deficiency across females under highly variable dietary conditions), indexing faecal steroid excretion by cholestanone concentrations may be appropriate. Because one of our long-standing interests is in measuring the impact of environmental stressors on reproductive fitness of free-ranging baboons (Wasser, 1983; Wasser and Barash, 1983; Wasser and Starling, 1988), we anticipate that cholestanone indexing may indeed be useful.

This research was funded by grants to $S$. K. Wasser from the National Institutes of Mental Health and the Smithsonian Institution. Support was also provided by the Smithsonian Institution Scholarly Studies Program, the Women's Committee of the Smithsonian Institution and the Friends of the National Zoo. Study animals, housing, maintenance and animal care were generously provided by the Primate Research Unit of the National Institutes of Health. We are grateful for the assistance of N. Presley and B. Ferguson and to Marion Zoological, Inc., who provided most of the special diets at no charge. Finally, we thank J. Brown for valuable advice and comments on the manuscript.

\section{References}

Adlercreutz $\mathrm{H}$ and Jarvenpaa $\mathbf{P}$ (1982) Assays of estrogens in humans Journal of Steroid Biochemistry 17 639-645

Adlercreutz H, Martin F, Jarvenpaa P and Fotsis T (1979) Steroid absorption and enterohepatic recycling Contraception $20210-223$

Bamberg E, Möstl E, Patzi M and King GJ (1991) Pregnancy diagnosis by enzyme immunoassay of estrogens in feces from nondomestic species Journal of Zoo and Wildlife Medicine 22 73-77

Goldin BR, Adlercreutz H, Dwyer JT, Swenson L, Warram JH and Gorbach SL (1981) Effect of diet of excretion of estrogen in pre- and post-menopausal women Cancer Research 41 3771-3773

Goldin BR, Adlercreutz H, Gorbach SL, Warram JH, Dwyer JT, Swenson L and Woods MN (1982) Estrogen excretion patterns and plasma levels in vegetarian and omnivorous women New England Journal of Medicine 307 1542-1547

Grieger DM, Scarborough R, deAvila DM, Johnson HE and Reeves JJ (1990) Active immunization of beef heifers against luteinizing hormone: III. Evaluation of dose and longevity Journal of Animal Science 68 3755-3764

Kirkpatrick JF, Shideler SE and Turner JW (1990) Pregnancy determination in uncaptured feral horses based on steroid metabolites in urine-soaked snow and free steroids in feces Canadian Journal of Zoology 68 2576-2579

Kurup AP, Jayakumari N, Indira M, Kurup GM, Vargheese T, Mather A, Goodman GT, Calkins BM, Kessie G, Turjman N and Nair PP (1984) Diet, nutrition intake and metabolism in populations at high and low risk for colon cancer. Composition, intake and excretion of fiber constituents American Journal of Clinical Nutrition 40 942-946

Lasley BL and Kirkpatrick JF (1991) Monitoring ovarian function in captive and free-ranging wildlife by means of urinary and fecal steroids Joumal of Zoo and Wildlife Medicine 22 23-31

Möstl E, Choi HS, Wurm W, Ismail N and Bamberg E (1984) Pregnancy diagnosis in cows and heifers by determination of oestradiol- $17 \alpha$ in faeces British Veterinary Joumal 140 287-291

Nair PP (1984) Diet, nutrition intake and metabolism in populations at high and low risk for colon cancer. Introduction: correlates of diet, nutrient intake and metabolism in relation to colon cancer American Journal of Clinical Nutrition $40880-886$

Nair PP, Gordon M and Rebach J (1967) The enzymatic cleavage of the carbonnitrogen bond in $3 \alpha, 7 \alpha, 12 \alpha$ tri-OH $5 \beta$ cholan-24-oyl glycene Journal of Biological Chemistry 242 7-11

Nair PP, Turjman N, Goodman GT, Guidry C and Calkins BM (1984) Diet, nutrition intake and metabolism in populations at high and low risk for colon cancer. Metabolism of neutral sterols American Journal of Clinical Nutrition 40 931-936

Perez LE, Czekala NM and Weisenseel KA (1988) Excretion of radiolabeled estradiol metabolites in the slow loris (Nycticebus coucang) American Journal of Primatology 16 321-330

Risler L. Wasser SK and Sackett GP (1987) Measurement of excreted steroids in Macaca nemestrina American Journal of Primatology 12 91-100

Safar-Hermann N, Ismail MN, Choi HS, Möstl E and Bamberg E (1987) Pregnancy diagnosis in zoo animals by estrogen determination in feces Zoo Biology 6 189-193

Shackleton CHL (1974) Steroid excretion in the neo-natal period: a comparative study of the excretion of steroids by human, ape and thesus monkey infants Journal of Steroid Biochemistry 5 113-118

Shideler S, Haggerty MA and Lasley BL (1989) The excretory time course and metabolic fate of ovarian and adrenal steroids in Macaca mulatta Biology of Reproduction Supplement I, 40105 (Abstract)

Shille VM, Wing AE, Lasley BL and Banks JA (1984) Excretion of radiolabeled estradiol in the cat (Felis catus, L.): a preliminary report Zoo Biology 3 201-209

Turjman N and Jacob C (1984) Amberlite XAD-2 in the determination of human fecal bile acids American Journal of Clinical Nutrition 40 957-960

Turjman N and Nair PP (1984) Diet, nutrition intake, and metabolism in populations at high and low risk for colon cancer. In situ bromination for the separation of the cholesterol-cholestanol pair in human fecal extracts American Journal of Clinical Nutrition $40952-956$

Wasser SK (1983) Reproductive competition and cooperation among female yellow baboons. In Social Behavior of Female Vertebrates pp 349-390 Ed. SK Wasser. Academic Press, New York

Wasser SK and Barash DP (1983) Reproduction suppression among female mammals: implication for biomedicine and sexual selection theory Quarterly Review of Biology 58 513-538

Wasser SK and Starling AK (1988) Proximate and ultimate causation of reproductive suppression among female yellow baboons at Mikumi National Park, Tanzania American Journal of Primatology 16 97-121

Wasser SK, Risler $\mathbf{L}$ and Steiner RA (1988) Excreted steroids in primate feces over the menstrual cycle and pregnancy Biology of Reproduction 39 862-872

Wasser SK, Monfort SL and Wildt DE (1991) Rapid extraction of faecal steroids for measuring reproductive cyclicity and early pregnancy in free-ranging yellow baboons (Papio cynocephalus cynocephalus) Journal of Reproduction and Fertility 92 415-423

Ziegler TE, Sholl SA, Scheffler G, Haggerty MA and Lasley BL (1988) Excretion of estrone, estradiol and progesterone in the urine and feces of the female cotton-top tamarin (Saguinus oedipus oedipus) American Joumal of Primatology 17 185-195 